British Journal of Nutrition (2017), 117, 93-107

(C) The Authors 2017. This is an Open Access article, distributed under the terms of the Creative

Commons Attribution-NonCommercial-NoDerivatives licence (http://creativecommons.org/licenses/by-nc-nd/4.0/),

which permits non-commercial re-use, distribution, and reproduction in any medium, provided the original work

is unaltered and is properly cited. The written permission of Cambridge University Press must be obtained for

commercial re-use or in order to create a derivative work.

\title{
Can probiotics modulate human disease by impacting intestinal barrier function?
}

\author{
Peter A. Bron ${ }^{1}{ }^{*}+$, Michiel Kleerebezem ${ }^{2} \dagger$, Robert-Jan Brummer ${ }^{3}$, Patrice D. Cani ${ }^{4}$, Annick Mercenier ${ }^{5}$, \\ Thomas T. MacDonald ${ }^{6}$, Clara L. Garcia-Ródenas ${ }^{5}$ and Jerry M. Wells ${ }^{2}$ \\ ${ }^{1}$ NIZO Food Research and BE-Basic Foundation, Kernhemseweg 2, 6718ZB Ede, The Netherlands \\ ${ }^{2}$ Wageningen University, Host Microbe Interactomics Group, De Elst 1, 6708WD Wageningen, The Netherlands \\ ${ }^{3}$ Faculty of Medicine and Health, Örebro University, Fakultetsgatan 1, SE-701 82 Örebro, Sweden \\ ${ }^{4}$ Metabolism and Nutrition Research Group, WELBIO - Walloon Excellence in Life Sciences and BIOtechnology, Louvain Drug \\ Research Institute, Université catholique de Louvain, Avenue E. Mounier, 73 B1.73.11, 1200 Brussels, Belgium \\ ${ }^{5}$ Nestlé Research Center, Nutrition and Health Research, route du Jorat 57, 1000 Lausanne 26, Switzerland \\ ${ }^{6}$ Barts and The London school of Medicine and Dentistry, Blizard Institute, Queen Mary University of London, Mile End Road, \\ London E1 4NS, UK
}

(Submitted 2 May 2016 - Final revision received 29 September 2016 - Accepted 25 October 2016 - First published online 19 January 2017)

\section{Abstract}

Intestinal barrier integrity is a prerequisite for homeostasis of mucosal function, which is balanced to maximise absorptive capacity, while maintaining efficient defensive reactions against chemical and microbial challenges. Evidence is mounting that disruption of epithelial barrier integrity is one of the major aetiological factors associated with several gastrointestinal diseases, including infection by pathogens, obesity and diabetes, necrotising enterocolitis, irritable bowel syndrome and inflammatory bowel disease. The notion that specific probiotic bacterial strains can affect barrier integrity fuelled research in which in vitro cell lines, animal models and clinical trials are used to assess whether probiotics can revert the diseased state back to homeostasis and health. This review catalogues and categorises the lines of evidence available in literature for the role of probiotics in epithelial integrity and, consequently, their beneficial effect for the reduction of gastrointestinal disease symptoms.

Key words: Probiotics: Gut microbiota: Gut barrier: Immunity: Gastrointestinal disorders

The human intestine contains a dense and complex community of microbes, and many representatives permanently inhabit this niche ${ }^{(1,2)}$. In addition to the resident microbiota, various bacteria transiently pass through the intestine as a consequence of ingestion - for example in fermented food products, or as supplements containing probiotics ${ }^{(3,4)}$. The latter are defined as 'live micro-organisms that, when administered in adequate amounts, confer a health benefit on the host ${ }^{(5,6)}$. In the intestinal tract, a single layer of epithelial cells forms a physical barrier between the intestinal lumen, the lamina propria and the mucosal-associated lymphoid tissue. In addition, mucus secreted by goblet cells in the epithelium serves to spatially compartmentalise the bacteria to the lumen and prevent bacterial colonisation of the epithelium ${ }^{(7-9)}$. Mice lacking Muc2, the major secreted mucin in the intestine, develop spontaneous colitis demonstrating its important barrier function ${ }^{(10)}$. Mucosal Ig and antimicrobial peptides (AMP) and proteins secreted by the epithelial cells serve to enhance the barrier function of the epithelium through immune exclusion and killing of bacteria $^{(11)}$. Moreover, in mucus-deficient mice, the ileal region of the intestine appears to be protected from excessive inflammatory responses by activation of epithelial repair and barrier maintenance pathways through the IL-22-STAT regulatory axis ${ }^{(12)}$.

The first direct evidence for the role of epithelial integrity in preventing intestinal inflammation came from a chimeric mouse model in which parts of the small bowel epithelium expressed $\mathrm{N}$-cadherin instead of E-cadherin, thereby disrupting the E-cadherin homotypic interactions that help maintain junctional integrity $^{(13)}$. The regions of the intestine expressing $\mathrm{N}$-cadherin were more permeable than the areas expressing E-cadherin and developed focal lesions because of inflammation. Since then, studies in several different knockout mice have shown that defects in the pathways maintaining epithelial integrity, epithelial stress

Abbreviations: CD, Crohn's disease; NEC, necrotising enterocolitis; TJ, tight junction; TLR, Toll-like receptor; UC, ulcerative colitis.

* Corresponding author: P. A. Bron, fax +32 276200 44, email Publications@ilsieurope.be

$\dagger$ These authors contributed equally to this work. 
responses or the regulation of mucosal immune responses lead to barrier destruction and colitis triggered by bacterial antigens and microbe-associated molecular patterns $\left(\right.$ MAMP) ${ }^{(14-19)}$.

Despite the role of commensal MAMP in triggering inflammatory responses, homeostasis is not maintained by a 'passive' mechanism of lack of recognition. In contrast, Toll-like receptor (TLR) activation by commensal bacteria was shown to play a crucial role in the recovery from epithelial damage induced by dextran sodium sulphate (DSS) ${ }^{(20-24)}$. Similarly, mice with a knockout of NEMO (ikappa kinase $\gamma$ ), an activator of $\mathrm{NF}-\kappa \mathrm{B}$, develop spontaneous colitis because of the role of $\mathrm{NF}-\kappa \mathrm{B}$ in inducing epithelial repair and innate effector mechanisms in the intestine ${ }^{(18)}$. TLR signalling and in particular TLR-2 signalling and protein kinase C (PKC) $\alpha$ and PKC $\delta$ activation have also been implicated in tight-junction (TJ) function modulation and epithelial permeability ${ }^{(25)}$.

A limited number of studies report the impact of probiotics on barrier integrity in (healthy) human volunteers, although several plausible direct and indirect mechanisms of bacterial modulation of barrier function have been postulated (Fig. 1). For example, Gotteland et al. ${ }^{(26)}$ evaluated the impact of consumption of Lactobacillus rhamnosus GG in healthy human volunteers upon epithelial barrier challenge by treatment with the nonsteroidal anti-inflammatory drug indomethacin. The authors reported that the consumption of live L. rhamnosus GG protected the integrity of the gastric mucosal barrier, but had no effect at the intestinal level ${ }^{(26)}$, highlighting the differences in

(a)

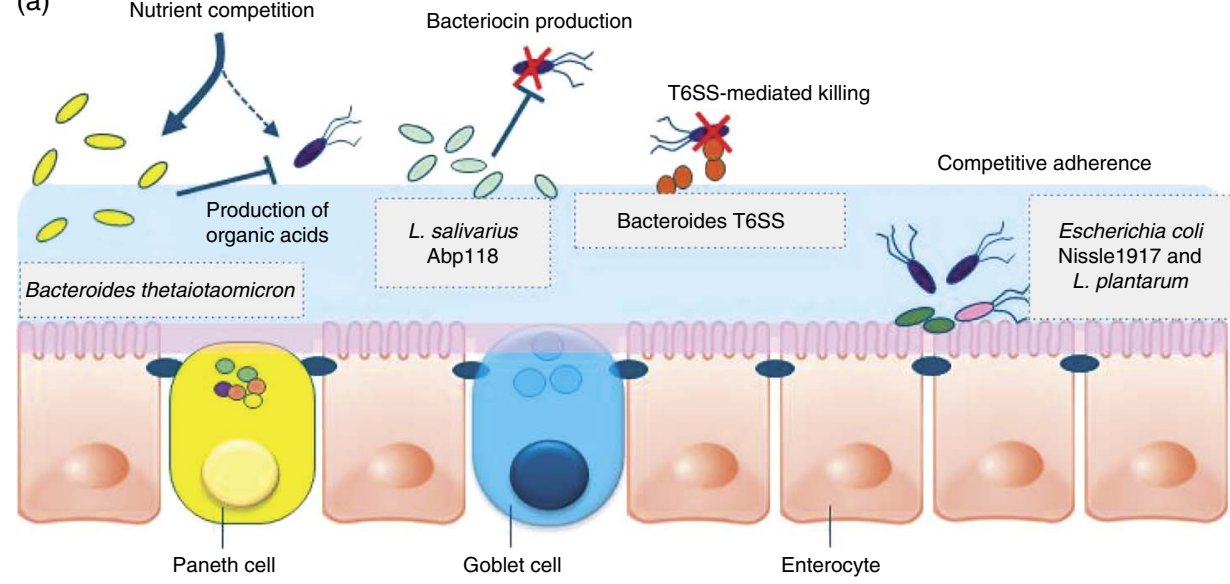

(b)

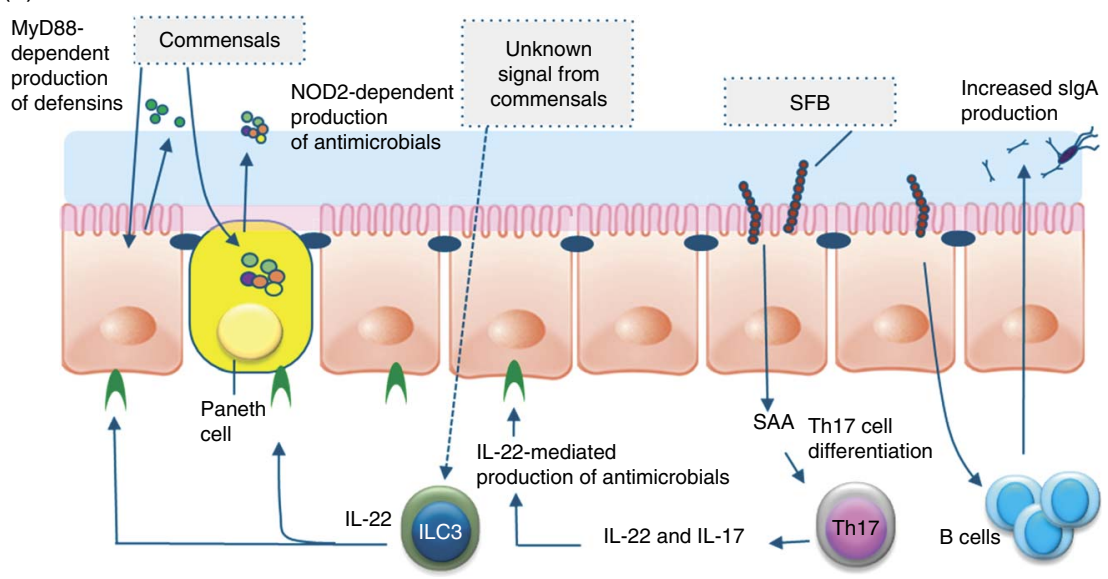

Fig. 1. Direct and indirect mechanisms by which commensals or probiotics can antagonise pathogens. Graphical display of exemplary direct (a) and indirect (b) mechanisms of barrier function modulation by bacterial (probiotic) interaction. (a) Direct mechanisms of barrier function modulation by interaction of commensals and probiotics. Bacteria can compete with enteric pathogens by competition for carbohydrates depending on the diet ${ }^{(227)}$. A probiotic strain of Lactobacillus salivarius UCC118 produces a bacteriocin in vivo that can significantly protect mice against infection with the invasive foodborne pathogen Listeria monocytogenes ${ }^{(36)}$. In diverse Bacteroides species, a type VI secretion system (T6SS) mediates cell-contact-dependent mechanisms of inter-bacterial antagonism via the export antibacterial proteins $^{(228)}$. Probiotics have been shown to inhibit the colonisation of pathogens through competition for common receptors of adhesion ${ }^{(48)}$. (b) Indirect mechanisms of pathogen antagonism. Recognition of microbe-associated molecular patterns by host pattern recognition receptors such as TLR and NLR activate immune defences and protect against infection. TLR signalling induces expression of defensins in enterocytes and antimicrobial factors in Paneth cells via the myeloid differentiation primary response 88 (MYD88) activation of NF-KB leading to the production of antimicrobial peptides. Similarly, nucleotide-binding oligomerisation domain 2 (NOD2) recognition of bacterial peptidoglycan induces cryptdin expression by Paneth cells. Sensing of an unknown signal from commensal microbes stimulates type 3 innate lymphoid cells (ILC) to secrete IL-22, which signals through the receptor (IL-22R) on intestinal epithelial cells to increase expression of the fucosyltransferase (FUT), mucin expression and antimicrobials, including regenerating family member 3 (Reg3) proteins. Segmented filamentous bacteria (SFB) closely associate with the ileum epithelium and stimulate maturation of the B- and T-cell compartments leading to enhanced IgA production by B cells and serum amyloid A (SAA)-dependent T helper 17 (Th17) cell differentiation. Th17 cells produce inflammatory cytokines and IL-22, which stimulate innate immune defence mechanisms to fight off infections. 
physiology of the epithelial barrier in different locations of the gastrointestinal tract. Karczewski et al. ${ }^{(25)}$ performed TJ staining in duodenal samples obtained from healthy volunteers after perfusion with Lactobacillus plantarum WCFS1, revealing that the TJ localisations of scaffold protein ZO-1 (zonula occludens-1, also known as tight junction protein-1) and the transmembrane protein occludin were significantly increased by the interaction with this bacterium. Subsequently, these authors showed that the same strain conferred protection against chemically induced barrier disruption in an in vitro Caco- 2 cell line model, involving a TLR-2-dependent signalling pathways ${ }^{(25)}$. These studies imply that probiotic interventions are a plausible approach to enhance epithelial barrier function in human subjects, possibly in a location-specific (gastric $v$. intestinal) manner.

Increased mucosal permeability and loss of epithelial integrity are recognised to play a role in the pathophysiology of a variety of (gastrointestinal) disorders, including the challenge by intestinal pathogens, inflammatory bowel disease (IBD), irritable bowel syndrome (IBS), obesity and the metabolic syndrome and necrotising enterocolitis (NEC). One hallmark of all these disorders is the involvement of a compromised barrier function in the pathophysiology. Thus, many probiotic studies have been targeting patient populations or animal models for human diseases, to evaluate their protective capacity on clinical parameters, including barrier function. Below, we review the state of the art of these approaches and propose future strategies aiming to further substantiate our understanding of the mode of action of probiotics.

\section{Pathogen challenges to the barrier}

The mucosal barrier can be challenged by encounters with bacterial or viral pathogens; however, for obvious ethical reasons, it is not trivial to perform well-controlled human infection studies. As an alternative, attenuated pathogenic bacteria, which were developed as oral vaccines, have been used for experimental challenge studies in humans ${ }^{(27)}$. The attenuated bacterial pathogens generally lead to mild diarrhoea, offering a model system for controlled enteric pathogen challenge studies in human individuals ${ }^{(28,29)}$. However, it remains unclear whether these (more or less) attenuated enteric pathogens have similar effects on the mucosal barrier function as compared with the pathogenic strains they were derived from. Nevertheless, these models have been used to study the protective capacity of probiotics and other dietary ingredient interventions, with generally poor success rates for probiotics in the amelioration of diarrhoea symptoms ${ }^{(30,31)}$. Several studies have evaluated the potential of probiotics in eradication therapy of Helicobacter pylori ${ }^{(32)}$ and the prevention of rotavirus-caused diarrhoea in children ${ }^{(33,34)}$, although with a variable outcome.

Rodent models offer more flexibility and control for challenge studies with enteric pathogens and in examining the potential of probiotics to affect the efficacy of infection. In this area, various rodent in vivo ${ }^{(35)}$ infection models have demonstrated that probiotics can attenuate the severity of infection caused by several gastrointestinal pathogens, including $H$. pylori, Citrobacter rodentium, Listeria monocytogenes and Salmonella typhimurium $^{(36-41)}$. In many cases, the molecular mechanisms behind the positive effects remain unknown. Various mechanisms of probiotic action have been postulated that can explain their positive effects in enteropathogen infection models, although in only few of these scenarios there is a direct and pivotal role established for their effect on mucosal barrier function $^{(35)}$.

The presence of commensal bacteria can inhibit the efficacy of enteropathogens via 'colonisation resistance', which encompasses a variety of molecular mechanisms involving microbe-microbe and/or microbe-host interactions ${ }^{(42,43)}$. Ingested probiotic bacteria may modulate the endogenous microbiota composition by competing for (micro-)nutrients and/or the production of (secondary) metabolic products, thereby modulating the endogenous microbiota composition and/or activity, which may affect colonisation resistance and risk or severity of enteric pathogen infection ${ }^{(43)}$.

Probiotics can produce antimicrobial compounds that may have an impact on the pathogenic bacteria directly, or via their effects on the endogenous microbiota. For example, Lactobacillus reuteri can produce reuterin, a secondary metabolite with broadspectrum antimicrobial activity that can modulate the microbiota composition, as well as directly inhibit enteric pathogens ${ }^{(44)}$. Alternatively, probiotics may produce broad- or narrow-spectrum bacteriocins, which are small ribosomally synthesised peptides that inhibit the growth of other bacteria ${ }^{(45)}$, which may affect enteric pathogens directly. A well-developed example of such bacteriocin is the class II bacteriocin Abp118 that is produced by Lactobacillus salivarius UCC118 and effectively inhibits L. monocytogenes infection and barrier disruption in vivo in a mouse model ${ }^{(36)}$. Probiotics may also directly compete for mucosal adherence sites with pathogenic bacteria, a mechanism termed competitive exclusion ${ }^{(46)}$. However, in many cases the mechanism of anti-adherence remains unclear. A mannosespecific adhesin of L. plantarum has been identified that is proposed to play a role in the competitive exclusion of FimHdependent adhesion of enteropathogenic Escherichia coli (EPEC), or other mannose adhesion-dependent enteric pathogens (e.g. S. typhimurium $)^{(47,48)}$. Besides such direct competitive epithelial binding, other mechanisms may also underlie competitive exclusion such as the degradation of mucosal surface receptors by secreted enzymes, or the production of receptor analogues or bio-surfactants. However, in light of recent insights about the mucus barrier, the in vivo relevance of in vitro studies evaluating the inhibition of pathogen adherence to cell lines might be questioned. This is because of the fact that commensal contact with epithelial cells is very limited and hardly observed in vivo, because of the presence of a physical mucus barrier. In the colon, a thick firm layer of mucus overlays the epithelium and is devoid of bacteria, despite the large numbers residing in the lumen ${ }^{(49)}$. In the small intestine, the mucus layer is thinner, but bacteria are rarely seen in contact with the epithelium ${ }^{(8)}$, the exception being segmented filamentous bacteria in mice that have an atypical and intimate association with enterocytes ${ }^{(50)}$. In contrast to gram-positive probiotic strains, several enteric gram-negative pathogens possess flagella, which propel them through mucus. The probiotic E. coli Nissle (EcN) is flagellated and motile and thus has increased potential to inhibit pathogen adherence and invasion. EcN has been shown to inhibit invasion of various 
epithelial cell lines by Yersinia enterocolitica, Shigella flexneri, S. typhimurium and L. monocytogenes, via secretion of an unidentified factor rather than competition for receptors $^{(51)}$.

Many pathogens influence barrier permeability through production of toxins that disrupt TJ and/or cause increased secretion or decreased absorption of fluids and electrolytes ${ }^{(52,53)}$. Bifidobacterium breve strain Yakult and Bifidobacterium pseudocatenulatum DSM20439 have been described to inhibit the expression of Shiga toxin in enterohemorrhagic E. coli (EHEC) 0157:H7 strains in vitro, as well as in vivo in a mouse infection model ${ }^{(54)}$. This effect appears relatively unspecific, as subsequent work illustrated Shiga toxin expression inhibition in EHEC in vitro by fifteen different probiotics, depending on their capacity to produce organic acids ${ }^{(55)}$. A more specific mechanism has been proposed for probiotic yeast Saccharomyces boulardii that secretes a protease that can degrade Toxin A that is produced by Clostridium difficile ${ }^{(56)}$. Lesions in the epithelium can also be caused by cytoskeleton rearrangements induced by colonisation and invasion of enteropathogens. In vitro, these virulence mechanisms cause a drop in transepithelial electrical resistance (TEER) of epithelial cell monolayers. Lactobacillus strains of intestinal origin have been shown to inhibit pathogen-induced disruption of epithelial integrity. Lactobacillus acidophilus $\mathrm{LB}^{(57)}$ and Lactobacillus belveticus $\mathrm{R} 0052^{(58)}$ have been shown to antagonise the cytoskeleton rearrangements caused by EPEC in vitro. Similar studies have shown that $L$. helveticus strain R0052 $2^{(58)}$ L. plantarum $299 \mathrm{v}^{(59,60)}$ and Lactobacillus casei DN-114001 016 reduce the drop in TEER caused by infection of T84 intestinal cells with EHEC and EPEC.

More recently, the concept of indirect pathogen antagonism arose by the recognition that microbial colonisation can stimulate innate and adaptive immune responses in the intestinal mucosa ${ }^{(11,62)}$. Stimulation of innate receptors expressed in the epithelium can enhance the production of inducible antimicrobials such as epithelial $\beta$-defensins and members of the antimicrobial C-type lectins in the gut ${ }^{(63)}$. Indeed, colonisation of germ-free mice and the expansion of bacteria after weaning caused an increased regenerating family member 3 (Reg3) production $^{(64,65)}$. However, some studies reported no change in production of defensins by commensal colonisation of the gut $^{(66,67)}$, which may be due to differences in the regulatory control of certain AMP. Several studies using epithelial cell lines in vitro have demonstrated the capacity of probiotics to differentially regulate defensins ${ }^{(68-71)}$. Apart from the induction of AMP, probiotics might affect the mucus barrier. This could be through bacterial interaction with innate cells in the mucosa producing cytokines (e.g. IL-22 ${ }^{(11)}$, IL- $8^{(72)}$ ) that can increase the expression of specific mucin genes. For example, in vitro studies have shown that adherent Lactobacillus spp. can stimulate MUC3 expression in human intestinal epithelial cells and thereby inhibit EPEC adherence ${ }^{(72-74)}$. Analogously, lipopolysaccharide (LPS) can stimulate expression and secretion of MUC5AC and MUC5B ${ }^{(75)}$, and thereby enhance mucus barrier function ${ }^{(75)}$. These examples illustrate the potential of probiotics to enhance epithelial and mucus barrier functions, thereby protecting the host against enteric pathogens.

\section{Obesity and diabetes}

Low-grade inflammation, and in particular endotoxaemia (i.e. relatively high amounts of gut microbiota-derived LPS in plasma), has been identified as a factor involved in the onset and progression of metabolic diseases associated with obesity (insulin resistance, type 2 diabetes) in human and rodent models ${ }^{(76-79)}$. A high fat content in the diet and changes in barrier function are considered to be important factors in endotoxaemia $^{(80,81)}$. Several studies have shown that both dietinduced and genetic obese and type 2 diabetic mice displayed changes in gut microbiota ${ }^{(76,77,82-86)}$. Among the reduced abundance bacterial groups were the bifidobacteria ${ }^{(87)}$, which in mice has been associated with reduced intestinal LPS levels and improved mucosal barrier function ${ }^{(88-92)}$. These observations are in agreement with the reduction of metabolic endotoxaemia, gut barrier dysfunction and inflammatory disorders that could be achieved in mice by prebiotic supplementation, which restored the bifidobacterial abundance in the intestinal microbiota $^{(76,83,93,94)}$. However, the precise mechanism underlying these health improvements remain unclear, and may not be entirely attributed to Bifidobacterium spp. ${ }^{(95)}$. Although rodent models have revealed the impact of prebiotic supplementation on obesity, type 2 diabetes and gut barrier function ${ }^{(96-99)}$, only few studies have been conducted in human obese and type 2 diabetic populations ${ }^{(100-102)}$. One of these studies described enhanced weight loss and improved glucose regulation in obese adults who consumed fructooligosaccharide (FOS) supplements $(21 \mathrm{~g} / \mathrm{d})$ for 12 weeks, which was tentatively associated with FOS-induced suppressed ghrelin and enhanced peptide YY production ${ }^{(100)}$. The second study showed that long-term synbiotic supplementation (Bifidobacterium longum and FOS) in sixty-six overweight non-alcoholic steatohepatitis patients could reduce endotoxaemia, insulin resistance, steatosis and several metabolic and inflammatory parameters ${ }^{(101)}$. Besides these studies using prebiotic and synbiotic supplementation in rodent models and human populations, several studies have reported on the beneficial impacts of probiotics on obesity and type 2 diabetes in rodent models. In many of these studies, diet-induced obesity models were used to induce metabolic dysfunction in the animal models to subsequently address the possible health beneficial role of probiotic supplementation ${ }^{(103)}$. In such a setting, various lactobacilli were shown to positively affect various metabolic disorder parameters. For example, Lactobacillus gasseri BNR17 reduced body weight and fat mass development in overweight rats ${ }^{(104,105)}$, whereas in high-fatdiet-induced obese mouse models L. plantarum 14 supplementation was shown to reduce the mean adipocyte size ${ }^{(106)}$ and Lactobacillus paracasei F19 could induce a reduction of total fat mass and plasma TAG possibly via a mechanism involving angiopoietin-like factor $4^{(107)}$. In contrast, L. acidophilus NCDC supplementation in diet-induced obese mice did not induce any significant changes in body fat composition and/or liver and muscle fat content ${ }^{(108)}$. Analogously, L. casei Shirota did not affect fat mass and body weight in diet-induced obese mice but, nevertheless, did induce a reduction of insulin resistance and endotoxaemia, illustrating that the impact on gut 
barrier function and glucose regulation can be elicited by mechanisms that are independent of body weight and fat mass development ${ }^{(109)}$. A few human intervention studies were also performed, including a study that suggests that specific Lactobacillus strains have an impact on body fat, weight and metabolic disorders. For example, the ingestion of $L$. gasseri SBT2055 for 12 weeks reduced fat-mass gain, body weight, waist:hip ratio in overweight subjects compared with placebo $^{(110)}$, an effect recently confirmed by the authors ${ }^{(111)}$. Jung et al. ${ }^{(112)}$ have shown that the ingestion of Lactobacillus gasseri BNR17, a strain showing beneficial effects in rodents, reduced weight and waist and hip circumference after 12 weeks of treatment. Sanchez et al. have observed that supplementation with L. rhamnosus CGMCC1.3724 $\left(1.6 \times 10^{8}\right.$ colony-forming units (CFU) of the strain per capsule with oligofructose and inulin) helped to lose more weight in women after the first 12 weeks, whereas it has no effect in men. Interestingly, while women in the placebo group regain weight during the weightmaintenance period, opposite changes were observed in women from the treated group who continued to lose body weight and fat mass. Finally, another study showed that the perinatal modulation of the gut microbiota by L. rhamnosus GG reduces excessive weight gain during the first years of life in children ${ }^{(113)}$, thereby suggesting that perinatal intervention may also be beneficial for the infants.

Several studies described a positive impact of Lactobacillus spp. supplementation on diet-induced metabolic disorders, including improved intestinal barrier function and reduced endotoxaemia. However, a recent study showed that in 3-weekold mice the high-dosage supplementation with Lactobacillus ingluviei $\left(4 \times 10^{10} \mathrm{CFU}\right)$ led to increased overall weight gain, as well as total liver weight, while not affecting fat mass despite increased transcription levels of the lipogenic markers (PPAR $\gamma$ and sterol regulatory element-binding protein 1c) in the gonadal fat mass ${ }^{(114)}$. The variability in the results obtained in these models imply that both the specific rodent model (age of the animals and the mode by which metabolic disorders are induced) and the choice of Lactobacillus spp. could have a major impact on the outcomes of these interventions. Nevertheless, in adult animals there are multiple indications that lactobacilli may positively affect different metabolic disorder parameters, including compromised barrier function and inflammatory status.

Analogous to the lactobacilli, bifidobacteria have also been evaluated for their capacity to improve metabolic disorders in diet-induced rodent models for obesity and diabetes ${ }^{(103)}$. For example, in a high-fat-diet-induced obesity model in rats, a mixture of three Bifidobacterium strains (B. pseudocatenulatum SPM 1204, B. longum SPM 1205 and B. longum SPM 1207) was shown to reduce body weight and adiposity, but it also reduced cholesterol (total, HDL-cholesterol and LDL-cholesterol), TAG, glucose, leptin and hepatic enzyme (aspartate aminotransferase, alanine aminotransferase and lipase) levels in plasma, suggesting beneficial effects of this strain mixture in high-fat-diet-induced obesity and type 2 diabetes $^{(115)}$. In a similar model, B. longum supplementation could compensate the decreased endogenous Bifidobacterium abundance induced by the high-fat diet, and led to reduced body weight gain, fat mass, insulin resistance, systolic blood pressure, as well as lowered metabolic endotoxaemia, and
IL-1 $\beta$ and intestinal myeloperoxidase levels in plasma. The authors proposed that these effects might be mechanistically linked to enhanced barrier function induced by B. longum supplementation via increased expression of intestinal REG-family proteins ${ }^{(116)}$. Notably, a recent study illustrated that in high-fat-diet-induced obese mice, the translocation of gram-negative Enterobacteriaceae to adipose tissue and blood was increased, which was accompanied by elevated inflammation status. This 'metabolic bacteremia' could be suppressed by dietary supplementation with Bifidobacterium animalis subsp. lactis 420, which not only normalised inflammation status but also corrected insulin sensitivity and hyperinsulinemia ${ }^{(117)}$. Intriguingly, this Bifidobacterium strain was also shown to competitively exclude the binding of pathogenic bacteria to the mucosa ${ }^{(118)}$ and improve TJ integrity ${ }^{(119)}$ in vitro, again pointing towards enhanced intestinal barrier function as the compensatory mode of action.

More recently, the role of another putative beneficial bacterium, namely Akkermansia muciniphila, has been discovered. Obese and diabetic mice treated with A. muciniphila exhibit a reduced body weight and fat mass gain, a reduced inflammation and metabolic endotoxaemia upon high-fat-diet feeding. Although the overall mechanisms are not fully elucidated, this bacterium reinforced the gut barrier function by increasing the production of specific endocannabinoids with anti-inflammatory properties, Reg $3 \gamma$, and increased the mucus layer thickness ${ }^{(120,121)}$. Taken together, a variety of rodent model studies indicate that probiotics may elicit beneficial impacts in metabolic disorders associated with obesity and diabetes. Moreover, several studies indicate that these effects may be exerted by a postulated role of probiotics in modulation of the intestinal barrier function, albeit via unknown molecular mechanisms. Importantly, very few studies have evaluated whether similar effects can be achieved in human studies, marking a major caveat in our understanding of the possibilities of probiotic benefits in human obesity and diabetes.

\section{Necrotising enterocolitis}

NEC is an acute inflammatory process in the immature intestine, which affects $5-10 \%$ of very low birth weight infants and results in high mortality, heavy complications and invalidating sequelae ${ }^{(122)}$. Several randomised clinical trials indicate a protective effect of probiotics in the prevention on NEC. Despite recent critical reviews and meta-analyses ${ }^{(123-127)}$ that support significant reduction in the incidence of severe NEC and mortality in preterm infants by probiotics, medical experts hesitate to recommend the routine use of a specific probiotic treatment and await large and well-designed safety and efficacy trials to complement the currently available pooled analysis of relatively small trials that use different probiotic strains ${ }^{(126,127)}$. Nevertheless, most experts agree on the potential of some probiotic strains to reduce the incidence and severity of NEC. In previous papers, it has been extensively discussed that immaturity of the intestinal barrier is amongst the major aetiological factors of $\mathrm{NEC}^{(128-134)}$ and may be modulated by probiotic administration.

Most probiotic trials in preterm infants have focused on the impact on intestinal colonisation as measured by faecal microbiota composition analyses ${ }^{(135-142)}$. These studies have 
illustrated that a variety of (mixtures of) probiotic strains or synbiotics can reduce the levels of potential pathogenic bacteria and yeast species in the faecal microbiota, which could contribute to the reduction of incidence and severity of NEC. An alternative scenario proposed that some probiotic strains such as $L$. reuteri ATCC 55730 could play a role in accelerating the gastrointestinal motility ${ }^{(143)}$ thereby preventing intestinal overgrowth, which is a proposed NEC risk factor.

Only two clinical trials that used the probiotic strain Bifidobacterium lactis CNCM I-3446 have addressed other components of the preterm barrier function. One of these studies demonstrated that this probiotic induced a faster decrease of intestinal permeability levels and, not surprisingly, an increased relative abundance of faecal bifidobacteria ${ }^{(144)}$. Although this small study was not powered to assess the impact on NEC, three infants developed the disease within the placebo group, whereas none developed NEC in the probiotic group. In a separate study that used the same probiotic, the expected bifidogenic effect was confirmed and was accompanied by reduced counts in faecal samples of potentially pathogenic bacteria (e.g. clostridia and enterobacteria ${ }^{(145)}$ ), which may be related to accompanying increased faecal SCFA levels and lower faecal $\mathrm{pH}^{(150)}$. Notably, this study also reported decreased calprotectin (marker for intestinal inflammation) and increased serum IgA levels in faecal samples ${ }^{(146)}$, supporting the proposed impact of this probiotic on barrier function either directly or via the decreased relative abundance of pathogenic bacterial groups.

Most studies that support a role of probiotics in the acceleration of appropriate barrier function establishment in the immature intestinal tract have been generated in neonatal animal models using immature pigs, rabbits or rats to mimic the preterm infant barrier and the NEC-associated inflammatory conditions. The available data obtained in such models support that some probiotic strains can reduce the incidence and/or severity of NEC by modulating diverse components of the intestinal barrier. These studies report favourable effects on the diversity of the commensal microbiota $^{(147-149)}$, including reduced luminal and mucosal colonisation, as well as translocation to extra-intestinal organs of pathogenic bacteria ${ }^{(150-152)}$. Barrier integrity improvements measured in these models include a decreased permeability to small solutes ${ }^{(153)}$, macromolecules $^{(147,153-156)}$ and endotoxin ${ }^{(157)}$. Moreover, in these models, the mucosal expression of various factors involved in barrier function regulation and maintenance could be normalised by probiotic supplementation, including TLR4 ${ }^{(158)}$ and TLR9 ${ }^{(159)}$, mucin and trefoil factor $(\text { TFF })^{(160)}$ and antimicrobial protein and peptides ${ }^{(161)}$. Probiotics were also shown to enhance enterocyte proliferation and migration ${ }^{(148)}$, to reduce apoptosis and promote epithelial cytoprotective responses $^{(160,162,163)}$, to improve the expression of the enterocyte injury markers intestinal-type and liver-type fatty-acidbinding proteins (I-FABP and L-FABP) ${ }^{(164)}$, to restore the expression and localisation of $\mathrm{TJ}$ and adherens junction proteins ${ }^{(160)}$ and to restore the thickness of the intestinal mucosal and muscle layers ${ }^{(164)}$. Most of these trials do not inform about the specificity of the probiotic preparation related to their gut barrier effects, as they focused on the effect of one single probiotic or a probiotic mixture. However, when phylogenetically close strains were compared, they generally differentially modulated both intestinal inflammation and barrier outcomes ${ }^{(148,158,165)}$.

In line with this, a trial in preterm piglets fed a probiotic blend (L. paracasei ATCC55544, B. animalis DSM15954 and Streptococcus thermophilus DSM15957) either alive or inactivated by $\gamma$-irradiation reported not a decrease but an increase in the rate of NEC in the probiotic-treated animals. This was associated with impaired paracellular permeability in the group fed dead probiotics, and with exacerbated expression of proinflammatory cytokines and reduced microbiota diversity in the group fed the live probiotic blend ${ }^{(166)}$. To the best of our knowledge, similar results have never been reported in preterm infants and, although cases of sepsis due to probiotic administration have been occasionally described in preterm ${ }^{(167)}$ and immunocompromised patients ${ }^{(168)}$, these cases remain rare. As discussed by the authors, the results in the piglet study may be explained by experimental bias and would require confirmation ${ }^{(166)}$. Nevertheless, this study fuels safety concerns of probiotic applications in the highly sensitive preterm infant population, and supports the request for larger-scale safety and efficacy studies mentioned above.

Taken together, the evidence in neonatal animal models supports that probiotics can strengthen a variety of the immature gut barrier components, which can contribute to reduced incidence and/or severity of NEC. However, only few human studies evaluated barrier function modulation by probiotics in preterm infants and largely focused on their impact on microbial colonisation and microbiota composition. Most of these studies reported reduced pathogen loads in the developing preterm intestine upon probiotic administration, and some of them accelerated maturation of specific barrier components. The preclinical data suggest probiotic specificity on their barrier modulatory activity and therefore the need for a careful evaluation of each probiotic preparation.

Overall, current knowledge could translate into recommended routine use of specific probiotics in preterm infants, provided that large-scale and well-designed multicentre validation studies confirm their efficacy and safety.

\section{Irritable bowel syndrome}

IBS is a gastrointestinal disorder characterised by the association between recurrent abdominal pain/discomfort and a change in stool consistency or frequency. IBS has been classified according to dominant symptomatology in subgroups as constipation-predominant, diarrohea-predominant and mixed-type IBS. The worldwide prevalence is estimated to be $10-20 \%$, thereby causing an important health and social burden with substantial medical costs ${ }^{(169,170)}$. Increased visceral perception and deregulated mucosal immune responses are characteristics of IBS directly related to deterioration of intestinal barrier function. After an initial report from Finland ${ }^{(171)}$, increasing evidence emerged on distinct and various alterations in gut microbial composition in subgroups of IBS patients around the globe $^{(171-175)}$. Separate analysis of the faecal and mucosaassociated microbiome in IBS revealed specific patterns and correlates with mucosal lymphocyte phenotypes ${ }^{(176)}$. Although 
the scientific debate is ongoing, this suggests that at least in subpopulations of the IBS patient pool the gut microbiota is likely contributing to disease symptoms through an altered fermentation process, a harmful modulation of enteric sensorimotor function, an impaired intestinal barrier function, sustained immune activation without macroscopic signs of inflammation and a harmful modulation of the brain-gut axis $^{(177-180)}$. Moreover, specific probiotics have demonstrated effects on barrier function ${ }^{(25)}$, suggesting these bacteria might have a beneficial impact on IBS symptom scores. Mostly, in vitro and ex vivo cell culture ${ }^{(181,182)}$, as well as animal models such as mice ${ }^{(181-183)}$ and rats ${ }^{(184,185)}$, have been used in which epithelial barrier integrity is experimentally disrupted before the addition of (mixtures of) a probiotic strain. Several of these studies demonstrated alleviation of IBS-like symptoms in animal models and importantly also showed restoration of barrier function, which was likely due to the enhanced expression of TJ proteins such as occludin, E-cadherin and claudin-1 observed in the probiotic-treated groups. Probiotics could be a promising treatment option in IBS, and several, often small-scale, randomised clinical trials have been performed with various strains or mixtures of strains. Overall, the results of these trials are difficult to interpret, because of the use of different strains and combinations thereof, as well as limitations in the study designs ${ }^{(186)}$. Nevertheless, the current consensus in the scientific community is that there is a beneficial potential of the administration of specific probiotics strains in IBS, but that more robust clinical trials are required ${ }^{(187-190)}$. Particularly, lactic acid bacteria have been selected as promising probiotic candidates in the treatment of IBS $^{(191)}$. Although the concept seems attractive, it is not well established that a multi-strain or multi-species probiotic therapy would be preferable to single-strain administration. Irrespective of the outcome of these trials, it remains to be established whether eventual beneficial effects of probiotic supplementation in IBS are mediated through effects on barrier function.

A further area that deserves attention is the combination of selected non-digestible polysaccharides and other prebiotic compounds with specific probiotic strains (denoted as synbiotics), which could favour the production of lactic acid and butyrate. Such approaches may stimulate synergistic effects of probiotics and the endogenous microbiota and their metabolites, and could provide new scenarios to generate beneficial health effects in IBS patients. This is of particular interest in the light of the significant differences that have been reported for the intestinal microbiota composition when comparing IBS patients and healthy controls in both adult ${ }^{(172)}$ and children ${ }^{(192)}$ cohorts. The role of butyrate is especially interesting in this perspective, because it has been shown to alleviate the perception of afferent visceral signalling and, as a consequence, could improve IBS symptoms ${ }^{(193)}$

More research is also required to improve the colonisation of probiotic bacteria, as well as to identify optimal duration and possibly interruption of probiotic therapy in IBS. Moreover, further work is needed to better understand the possible interplay between probiotics and the endogenous microbiota, which could affect IBS via various mechanistic scenarios. Another important step forward would be targeting of carefully characterised subpopulations on the basis of pathophysiology rather than symptomatology, enabling a more personalised approach in the future. In probiotic studies that target the IBS population, a careful characterisation of alterations along the microbe-gut-brain axis is highly recommended and may support eventual probiotic therapies in IBS. Inversely, in view of the importance of the microbe-gut-brain axis in IBS, it is plausible that therapeutic option may also be found in the improvement of certain aspects of brain function, including mood, stress response and processing, with the aim to improve symptoms in IBS patients, possibly by altering microbial composition and/or activity in the intestine.

\section{Inflammatory bowel disease}

IBD is the overall term used to describe 2 idiopathic inflammatory diseases of the gut, namely Crohn's disease (CD) and ulcerative colitis (UC). These diseases, however, are quite different. CD can affect any part of the bowel but predominantly the terminal ileum and colon and is characterised by granulomatous, patchy, transmural mononuclear inflammation. In contrast, UC only affects the colon and the lesions are mucosal and continuous, with massive neutrophil infiltration, crypt abscesses, loss of goblet cells and epithelial cell damage. There is rather strong evidence that the immune response in $\mathrm{CD}$ is directed against the indigenous microbiota, but in UC the role of the microbiota is more contentious ${ }^{(194)}$. In active IBD, mucosal inflammation is accompanied by impaired barrier function ${ }^{(195)}$. The effect of inflammation on the barrier is likely to have many components. Pro-inflammatory cytokines such as interferon$\gamma^{(196)}$ and TNF- $\alpha$ make the epithelium leaky ${ }^{(197)}$. Cytokine IL-13 induces up-regulation of claudin 2, changing ion transport across the epithelium ${ }^{(198)}$. Matrix metalloproteinases such as matrix metallopeptidase (MMP)-12 made by activated macrophages and MMP-3 made by activated myofibroblasts degrade the epithelial basement membrane and disrupt epithelial cell adhesion leading to anoikis ${ }^{(199)}$. Free radicals and serine proteinases made by neutrophils directly kill epithelial cells.

Many studies have evaluated the potential of probiotics to contribute to IBD treatment. However, a fundamental problem with these studies is that different probiotics were used, either alone or in combination with other therapies. This makes the case that probiotics might work in IBD, but so far, we have not discovered the correct organism or combination of organisms. One should also note that IBD diseases are very serious conditions. For example, the induction of remission in $\mathrm{CD}$ requires powerful immunosuppressive agents such as corticosteroids, azathioprine and anti-TNF. In UC, the mainstay of remission induction in active disease is also corticosteroids. In view of the seriousness of these diseases, the idea that probiotics would be useful in treating active IBD is rather fanciful. Instead, there is much more of an opportunity to determine whether probiotics can help in maintaining remission, where their effects on maintaining the barrier are more relevant.

Three studies (with largely the same protocol) have investigated whether probiotic therapy prevents endoscopic recurrence of $\mathrm{CD}$ after surgical resection. It is very well established that recurrence of disease is first seen proximal to the anastomosis after resection. Although different probiotics were used in 
each study, the conclusions reached in each were consistent, indicating that no advantage was observed in the probiotictreated groups compared with the placebo controls ${ }^{(200-202)}$. Synbiotic therapies combine probiotics with prebiotics, and although an initial synbiotic study did not report any benefit in post-operative occurrence of $\mathrm{CD}^{(203)}$, a more recent study reported a slight but significant enhancement of the induction of remission of active $\mathrm{CD}^{(204)}$. Taken together, the use of probiotics as a therapy for active $\mathrm{CD}$ or for maintenance of disease remission has been disappointing, which has also been concluded in various recent reviews ${ }^{(205,206)}$. Notably, more promising results have been obtained for the use of probiotics in therapeutic applications to induce remission of UC, but also for supporting the maintenance of $\mathrm{UC}$ remission ${ }^{(205)}$. In a double-blind study comparing mesalazine with an oral preparation of viable $E$. coli strain Nissle (Serotype 06: K5: H1) with regard to their efficacy in preventing a relapse of the disease over a period of 12 weeks, probiotic treatment was equivalent to mesalazine ${ }^{(207)}$.

Pouchitis is an iatrogenic condition that occurs when a pouch is formed from terminal ileum and anastomosed onto the rectal stump following colectomy for UC, giving patients the opportunity to live without a stoma. Most patients develop some form of inflammation in the neo-reservoir (pouchitis). Standard therapy is the use of antibiotics such as metronidazole and ciprofloxacin. A number of studies in children and adults have demonstrated that taking a mixture of probiotic strains (VSL\#3) is effective in preventing pouchitis and also can play a significant role in treating active pouchitis ${ }^{(205)}$. It is likely that the efficacy of this probiotic preparation in pouchitis is due to the highly unusual situation in the pouch that forms a reservoir for ileal fluid, which could create an environment that allows probiotics to competitively inhibit potential harmful bacteria and fungi and thereby have its positive effects in pouchitis.

In terms of probiotic effects on the compromised epithelial barrier function in IBD, they may be exerted by different principal modes of action. First, probiotics may dampen mucosal inflammation activity, thereby allowing the epithelial function to return to normal. One intensively studied way to achieve suppression of mucosal inflammation is through the modulation of the balance and activity of the mucosal T-cell repertoire, particularly focused on stimulation of the regulatory T-cell populations ${ }^{(208)}$. Second, and more important in the context of this review, probiotics may directly affect the epithelial cells, leading to restoration of mucosal barrier integrity, thereby lowering the luminal antigenic stimulation that drives inflammation and suppressing inflammatory responses.

Many in vitro studies have demonstrated that probiotics can maintain the epithelial barrier and protect against cytokinedriven epithelial barrier dysfunction. Work by Polk et al. has taken this to a new level by isolating a P40 component of L. rhamnosus GG, which prevents cytokine-induced epithelial barrier dysfunction by signalling through the epidermal growth factor receptor ${ }^{(209)}$. When formulated for delivery into the mouse gut, P40 ameliorates colitis induced by DSS. In the same mouse model, a variety of studies highlights the potential of single strain or mixtures of probiotics to thicken the mucus layer and/or improve epithelial barrier function in general, with beneficial consequences for the inflammation read-outs in these animals ${ }^{(210-213)}$. A soluble factor from Bifidobacterium infantis also increases occludin and ZO-1 in epithelial cells in vitro and ameliorates colitis in IL-10 knock-out mice ${ }^{(214,215)}$. These data have also been taken into humans where it has been shown that $L$. plantarum perfusion in the duodenum, elicits structural changes in ZO-1 and occludin complexes that correlate with enhanced barrier function ${ }^{(25)}$. These examples do not provide a complete view of the available data, but there seems to be little doubt that probiotics and probiotic components can influence epithelial barrier integrity, and further molecular characterisation may resolve how specific probiotic components can affect the receptors and pathways they modulate. These insights could reinforce the specific role of probiotics in the treatment of UC and pouchitis, but is unlikely to change the perspective on effective probiotic treatment or maintenance of remission in CD.

\section{Concluding remarks}

Intestinal barrier integrity is a hallmark of gut health and a reflection of appropriate microbiota-accommodating homeostasis of mucosal function, which is orchestrated to combine maximised absorptive capacity with appropriate defensive reactions against chemical and microbial challenges. Many factors contribute to mucosal barrier function, including epithelial integrity, which is protected by the mucus layer that creates a physicochemical barrier that prevents direct contact of luminal challenges with the epithelia and is further supported by innate and adaptive immune functions. The endogenous microbiota play a key role in establishing mucosal barrier function development in infancy, but also in maintenance of this function during later life ${ }^{(216)}$.

The production of butyrate by the fermentative activity of the microbiota has been reported to increase production of secreted mucus and support regulatory T-cell functions in the gut ${ }^{(217-219)}$. Thus, modulation of the butyrate-producing sub-consortia of microbiota through prebiotics or dietary fibre supports the idea that nutritional strategies might also be effective in enhancing epithelial barrier function.

A striking example of how microbiota modulation can have a therapeutic effect is the use of faecal transplantation (bacteriotherapy) to treat $C$. difficile-associated disease, which has been successful even after the failure of multiple courses of antibiotics $^{(220,221)}$. With the growing success of faecal transplantation for $C$. difficile, patients suffering from other intestinal diseases such as IBD or the metabolic syndrome have been enrolled for faecal transplantation. Indeed, recent studies on $\mathrm{UC}^{(222)}$ and the metabolic syndrome ${ }^{(223)}$ indicated that gut microbiota infusion improved remission period length or insulin resistance, respectively, supporting the efficiency of gut microbiota transfer to improve some microbiota-related pathologies. However, studies on long-term efficiency of such microbiota transfer to elicit sustained health benefits still need to be addressed. Notably, the safety of the faecal material that is used for transplantation cannot be entirely assessed, because of the complexity of the microbial community. Consequently, there is an increasing interest in strategies aiming to define a well-characterised microbial cocktail of selected intestinal microbes that can effectively deliver the same 
health-promoting functionality as faecal donations, and replace faecal transplantation.

A compromised intestinal barrier is associated with several human gut-related disorders, for example IBD, NEC and lowgrade inflammation associated with the metabolic syndrome (obesity and diabetes). In addition, several other diseases also appear to be associated with a 'leaky' gut phenotype, including the post-infectious subtype of IBS $^{(224)}$, and possibly also allergy $^{(225)}$. Several lines of evidence indicate that probiotics can influence various aspects of intestinal barrier function (see above), which would support their therapeutic potential in diseases involving a dysfunctional gut barrier. However, most of the probiotic barrier effects were studied in in vitro cell line and animal models and the translation of these results to human efficacy in vivo in at risk or diseased populations remain virtually unexplored. Only very few studies using probiotics have directly evaluated mucosal barrier function in human volunteers, and in the studies where this parameter was measured healthy volunteers rather than diseased populations were typically targeted $^{(25,26)}$. Notably, both positive ${ }^{(144,226)}$ and negative ${ }^{(26,227)}$ impacts of probiotic consumption on barrier function have been reported, suggesting that a balanced view is required to evaluate their capacity to modulate intestinal barrier function in humans, particularly when severely compromised patient groups are targeted. Importantly, in the attempt to translate the results obtained in in vitro studies and experiments that use inbred animals, one should take into account that (healthy as well as diseased) humans are highly individual. Notably, it is commonly seen that molecular responses elicited by dietary interventions in humans are small in comparison with the differences observed between participating individuals per se. This level of individuality has been captured in the 'bandwidth of health' concept, which may explain the unpredictable distributions of responders and non-responders in nutritional intervention trials $^{(3,228)}$. Therefore, high-resolution, molecular phenotyping of dietary trial participants may offer new avenues to select subgroups of individuals predicted to be more responsive to the molecular response elicited by the probiotic treatment, for example, are predicted to benefit from a specific mechanism of barrier function improvement. These avenues would evolve to a more personalised nutrition approach and abandon the 'one size fits all' concept that is used in most studies to date.

Despite the difficulties in translating in vitro and animal study outcomes to human populations, a variety of studies imply that mucosal barrier function can be improved by probiotic treatment. This starting point underpins the need for studies in welldiagnosed diseased populations (e.g. including high resolution molecular profiling) where this health parameter is directly assessed in a probiotic intervention regimen. The current literature does not report this type of human studies, which may provide pivotal scientific support for the health-promoting therapeutic potential of probiotic treatment in disease, with a plausible underlying mode of action.

\section{Acknowledgements}

This work was conducted by an expert group of the European branch of the International Life Sciences Institute (ILSI Europe).
The authors thank Dr Arthur Ouwehand who is a member of the Probiotics Task Force for his active contribution to this work.

The expert group received funding from the ILSI Europe Probiotic Task Force. Industry members of this task force are listed on the ILSI Europe website at www.ilsi.eu. For further information about ILSI Europe, please email info@ilsieurope.be or call +32 277100 14. The opinions expressed herein and the conclusions of this publication are those of the authors and do not necessarily represent the views of ILSI Europe, nor those of its member companies. P. D. C. is a research associate at FRS-FNRS (Fonds de la Recherche Scientifique), and P. D. C. is the recipient of grants from FNRS and the French Cancer Research Association (ARC). This work was supported by the Fonds de la Recherche Scientifique - FNRS for the FRFS-WELBIO under grant no. WELBIO-CR-2012S-02R. This work is supported in part by the Funds InBev-Baillet Latour (Grant for Medical Research 2015). P. D. C. is a recipient of an ERC Starting Grant 2013 (European Research Council, Starting grant no. 336452-ENIGMO).

P. A. B. and M. K. had responsibility for producing the final version of the article. This publication was coordinated by Dr Jackie Whyte and Dr Tobias Recker, Scientific Project Managers at ILSI Europe. All authors contributed to discussions and had input into writing the article.

All authors have completed and submitted the ICMJE Form for disclosure of potential conflicts of interest.

\section{References}

1. Claes IJJ, Garcia CEV \& Lebeer S (2015) Novel opportunities for the exploitation of host-microbiome interactions in the intestine. Curr Opin Biotechnol 32, 28-34.

2. van Baarlen P, Kleerebezem M \& Wells JM (2013) Omics approaches to study host-microbiota interactions. Curr Opin Microbiol 16, 270-277.

3. Bron PA, van Baarlen P \& Kleerebezem M (2012) Emerging molecular insights into the interaction between probiotics and the host intestinal mucosa. Nat Rev Microbiol 10, 66-78.

4. Cani PD (2014) Metabolism in 2013: the gut microbiota manages host metabolism. Nat Rev Endocrinol 10, 74-76.

5. Hill C, Guarner F, Reid G, et al. (2014) Expert consensus document: The International Scientific Association for Probiotics and Prebiotics consensus statement on the scope and appropriate use of the term probiotic. Nat Rev Gastroenterol Hepatol 11, 506-514.

6. Food and Agriculture Organization/World Health Organization (2002) Joint FAO/WHO working group report on drafting guidelines for the evaluation of probiotics in food, London, ON, Canada.

7. Johansson MEV, Larsson JMH \& Hansson GC (2011) The two mucus layers of colon are organized by the MUC2 mucin, whereas the outer layer is a legislator of host-microbial interactions. Proc Natl Acad Sci U S A 108, 4659-4665.

8. Loonen LMP, Stolte EH, Jaklofsky MTJ, et al. (2014) REG3ydeficient mice have altered mucus distribution and increased mucosal inflammatory responses to the microbiota and enteric pathogens in the ileum. Mucosal Immunol 7, 939-947.

9. Vaishnava S, Yamamoto M, Severson KM, et al. (2011) The antibacterial lectin RegIIIgamma promotes the spatial segregation of microbiota and host in the intestine. Science $\mathbf{3 3 4}$, $255-258$ 
10. Van der Sluis M, De Koning BAE, de Bruijn ACJM, et al. (2006) Muc2-deficient mice spontaneously develop colitis, indicating that MUC2 is critical for colonic protection. Gastroenterology 131, 117-129.

11. Rossi GA, van Baarlen P \& Wells JM (2013) Host-recognition of pathogens and commensals in the mammalian intestine. Curr Top Microbiol Immunol 358, 291-321.

12. Sovran B, Loonen LMP, Lu P, et al. (2015) IL-22-STAT3 pathway plays a key role in the maintenance of ileal homeostasis in mice lacking secreted mucus barrier. Inflamm Bowel Dis 21, 531-542.

13. Hermiston ML \& Gordon JI (1995) Inflammatory bowel disease and adenomas in mice expressing a dominant negative N-cadherin. Science 270, 1203-1207.

14. Takahashi N, Vereecke L, Bertrand MJM, et al. (2014) RIPK1 ensures intestinal homeostasis by protecting the epithelium against apoptosis. Nature $\mathbf{5 1 3}, 95-99$.

15. Tanaka H, Takechi M, Kiyonari H, et al. (2015) Intestinal deletion of Claudin-7 enhances paracellular organic solute flux and initiates colonic inflammation in mice. Gut 10, 1529-1538.

16. Guenther C, Martini E, Wittkopf N, et al. (2011) Caspase-8 regulates TNF-[agr]-induced epithelial necroptosis and terminal ileitis. Nature 477, 335-339.

17. Kaser A, Lee AH, Franke A, et al. (2008) XBP1 links ER stress to intestinal inflammation and confers genetic risk for human inflammatory bowel disease. Cell 134, 743-756.

18. Nenci A, Becker C, Wullaert A, et al. (2007) Epithelial NEMO links innate immunity to chronic intestinal inflammation. Nature 446, 557-561.

19. Welz PS, Wullaert A, Vlantis K, et al. (2011) FADD prevents RIP3-mediated epithelial cell necrosis and chronic intestinal inflammation. Nature 477, 330-334.

20. Rakoff-Nahoum S, Hao L \& Medzhitov R (2006) Role of tolllike receptors in spontaneous commensal-dependent colitis. Immunity 25, 319-329.

21. Vaishnava S, Behrendt CL, Ismail AS, et al. (2008) Paneth cells directly sense gut commensals and maintain homeostasis at the intestinal host-microbial interface. Proc Natl Acad Sci U S A 105, 20858-20863.

22. Menendez A, Willing BP, Montero M, et al. (2013) Bacterial stimulation of the TLR-MyD88 pathway modulates the homeostatic expression of ileal Paneth cell a-defensins. J Innate Immun 5, 39-49.

23. Liu AY, Destoumieux D, Wong A V, et al. (2002) Human beta-defensin-2 production in keratinocytes is regulated by interleukin-1, bacteria, and the state of differentiation. J Invest Dermatol 118, 275-281.

24. Rossi O, Karczewski J, Stolte EH, et al. (2013) Vectorial secretion of interleukin- 8 mediates autocrine signalling in intestinal epithelial cells via apically located CXCR1. BMC Res Notes 6, 431.

25. Karczewski J, Troost FJ, Konings I, et al. (2010) Regulation of human epithelial tight junction proteins by Lactobacillus plantarum in vivo and protective effects on the epithelial barrier. Am J Physiol Gastrointest Liver Physiol 298, G851-G859.

26. Gotteland M, Cruchet S \& Verbeke S (2001) Effect of Lactobacillus ingestion on the gastrointestinal mucosal barrier alterations induced by indometacin in humans. Aliment Pharmacol Ther 15, 11-17.

27. Davitt CJH \& Lavelle EC (2015) Delivery strategies to enhance oral vaccination against enteric infections. $A d v$ Drug Deliv Rev 90, 52-69.

28. Harro C, Chakraborty S, Feller A, et al. (2011) Refinement of a human challenge model for evaluation of enterotoxigenic
Escherichia coli vaccines. Clin Vaccine Immunol $\mathbf{1 8}$, 1719-1727.

29. Bovee-Oudenhoven IMJ, Lettink-Wissink MLG, Van Doesburg W, et al. (2003) Diarrhea caused by enterotoxigenic Escherichia coli infection of humans is inhibited by dietary calcium. Gastroenterology 125, 469-476.

30. Ten Bruggencate SJM, Girard SA, Floris-Vollenbroek EGM, et al. (2014) The effect of a multi-strain probiotic on the resistance toward Escherichia coli challenge in a randomized, placebo-controlled, double-blind intervention study. Eur J Clin Nutr 69, 385-391.

31. Ouwehand AC, Ten Bruggencate SJM, Schonewille AJ, et al. (2014) Lactobacillus acidophilus supplementation in human subjects and their resistance to enterotoxigenic Escherichia coli infection. Br J Nutr 111, 465-473.

32. Li S, Huang X li, Sui J zhe, et al. (2014) Meta-analysis of randomized controlled trials on the efficacy of probiotics in Helicobacter pylori eradication therapy in children. Eur J Pediatr 173, 153-161.

33. Saavedra JM, Bauman NA, Perman JA, et al. (1994) Feeding of Bifidobacterium bifidum and Streptococcus thermophilus to infants in hospital for prevention of diarrhoea and shedding of rotavirus. Lancet 344, 1046-1049.

34. Szajewska H, Wanke M \& Patro B (2011) Meta-analysis: the effects of Lactobacillus rhamnosus GG supplementation for the prevention of healthcare-associated diarrhoea in children. Aliment Pharmacol Ther 34, 1079-1087.

35. Bujalance C, Jimenez-Valera M, Moreno E, et al. (2014) Lack of correlation between in vitro antibiosis and in vivo protection against enteropathogenic bacteria by probiotic lactobacilli. Res Microbiol 165, 14-20.

36. Corr SC, Li Y, Riedel CU, et al. (2007) Bacteriocin production as a mechanism for the antiinfective activity of Lactobacillus salivarius UCC118. Proc Natl Acad Sci U S A 104, 7617-7621.

37. Johnson-Henry KC, Nadjafi M, Avitzur Y, et al. (2005) Amelioration of the effects of Citrobacter rodentium infection in mice by pretreatment with probiotics. I Infect Dis 191, 2106-2117.

38. Emara MH, Elhawari SA, Yousef S, et al. (2015) Emerging role of probiotics in the management of Helicobacter pylori infection: histopathologic perspectives. Helicobacter 21, 3-10.

39. Bermudez-Brito M, Munoz-Quezada S, Gomez-Llorente C, et al. (2015) Lactobacillus paracasei CNCM I-4034 and its culture supernatant modulate Salmonella-induced inflammation in a novel transwell co-culture of human intestinallike dendritic and Caco-2 cells. BMC Microbiol 15, 79.

40. Asahara T, Shimizu K, Takada T, et al. (2011) Protective effect of Lactobacillus casei strain Shirota against lethal infection with multi-drug resistant Salmonella enterica serovar Typhimurium DT104 in mice. J Appl Microbiol 110, $163-173$.

41. Zoumpopoulou G, Foligne B, Christodoulou K, et al. (2008) Lactobacillus fermentum ACA-DC 179 displays probiotic potential in vitro and protects against trinitrobenzene sulfonic acid (TNBS)-induced colitis and Salmonella infection in murine models. Int J Food Microbiol 121, 18-26.

42. Spees AM, Lopez CA, Kingsbury DD, et al. (2013) Colonization resistance: battle of the bugs or Ménage à Trois with the host? PloS Pathog 9, e1003730.

43. Derrien M \& van Hylckama Vlieg JET (2015) Fate, activity, and impact of ingested bacteria within the human gut microbiota. Trends Microbiol 23, 354-366.

44. Cleusix V, Lacroix C, Vollenweider S, et al. (2007) Inhibitory activity spectrum of reuterin produced by Lactobacillus reuteri against intestinal bacteria. BMC Microbiol 7, 101. 
45. Cotter PD, Hill C \& Ross RP (2005) Bacteriocins: developing innate immunity for food. Nat Rev Microbiol 3, 777-788.

46. Servin AL (2004) Antagonistic activities of lactobacilli and bifidobacteria against microbial pathogens. FEMS Microbiol Rev 28, 405-440.

47. Pretzer G, Snel J, Molenaar D, et al. (2005) Biodiversitybased identification and functional characterization of the mannose-specific adhesin of Lactobacillus plantarum. J Bacteriol 187, 6128-6136.

48. Adlerberth I, Ahrne SIV, Johansson ML, et al. (1996) A mannose-specific adherence mechanism in Lactobacillus plantarum conferring binding to the human colonic cell line HT-29. Appl Environ Microbiol 62, 2244-2251.

49. Jakobsson HE, Rodriguez-Pineiro AM, Schutte A, et al. (2015) The composition of the gut microbiota shapes the colon mucus barrier. EMBO Rep 16, 164-177.

50. Klaasen HLBM, Koopman JP, Poelma FGJ, et al. (1992) Intestinal, segmented, filamentous bacteria. FEMS Microbiol Lett 88, 165-179

51. Altenhoefer A, Oswald S, Sonnenborn U, et al. (2004) The probiotic Escherichia coli strain Nissle 1917 interferes with invasion of human intestinal epithelial cells by different enteroinvasive bacterial pathogens. FEMS Immunol Med Microbiol 40, 223-229.

52. Lu RY, Yang WX \& Hu YJ (2014) The role of epithelial tight junctions involved in pathogen infections. Mol Biol Rep 41, 6591-6610.

53. Hodges K \& Gill R (2010) Infectious diarrhea: cellular and molecular mechanisms. Gut Microbes 1, 4-21.

54. Asahara T, Shimizu K, Nomoto K, et al. (2004) Probiotic bifidobacteria protect mice from lethal infection with Shiga toxin-producing Escherichia coli O157: H7. Infect Immun 72, 2240-2247.

55. Carey CM, Kostrzynska M, Ojha S, et al. (2008) The effect of probiotics and organic acids on Shiga-toxin 2 gene expression in enterohemorrhagic Escherichia coli O157: H7. J Microbiol Methods 73, 125-132.

56. Castagliuolo I, LaMont JT, Nikulasson ST, et al. (1996) Saccharomyces boulardii protease inhibits Clostridium difficile toxin A effects in the rat ileum. Infect Immun 64, 5225-5232.

57. Lievin-Le Moal V, Amsellem R, Servin AL, et al. (2002) Lactobacillus acidophilus (strain LB) from the resident adult human gastrointestinal microflora exerts activity against brush border damage promoted by a diarrhoeagenic Escherichia coli in human enterocyte-like cells. Gut 50, 803-811.

58. Sherman PM, Johnson-Henry KC, Yeung HP, et al. (2005) Probiotics reduce enterohemorrhagic Escherichia coli O157: H7-and enteropathogenic E. coli O127: H6-induced changes in polarized T84 epithelial cell monolayers by reducing bacterial adhesion and cytoskeletal rearrangements. Infect Immun 73, 5183-5188.

59. Mangell P, Nejdfors $\mathrm{P}$, Wang M, et al. (2002) Lactobacillus plantarum 299v inhibits Escherichia coli-induced intestinal permeability. Dig Dis Sci 47, 511-516.

60. Michail S \& Abernathy F (2002) Lactobacillus plantarum reduces the in vitro secretory response of intestinal epithelial cells to enteropathogenic Escherichia coli infection. J Pediatr Gastroenterol Nutr 35, 350-355.

61. Parassol N, Freitas M, Thoreux K, et al. (2005) Lactobacillus casei DN-114 001 inhibits the increase in paracellular permeability of enteropathogenic Escherichia coli-infected T84 cells. Res Microbiol 156, 256-262.

62. Wells JM, Rossi O, Meijerink M, et al. (2011) Epithelial crosstalk at the microbiota-mucosal interface. Proc Natl Acad Sci U S A 108, 4607-4614.
63. Everard A, Geurts L, Caesar R, et al. (2014) Intestinal epithelial MyD88 is a sensor switching host metabolism towards obesity according to nutritional status. Nat Commun 5, 5648.

64. Cash HL, Whitham CV, Behrendt CL, et al. (2006) Symbiotic bacteria direct expression of an intestinal bactericidal lectin. Science 313, 1126-1130.

65. El Aidy S, van Baarlen P, Derrien M, et al. (2012) Temporal and spatial interplay of microbiota and intestinal mucosa drive establishment of immune homeostasis in conventionalized mice. Mucosal Immunol 5, 567-579.

66. Putsep K, Axelsson LG, Boman A, et al. (2000) Germ-free and colonized mice generate the same products from enteric prodefensins. J Biol Chem 275, 40478-40482.

67. Hase K, Eckmann L, Leopard JD, et al. (2002) Cell differentiation is a key determinant of cathelicidin LL-37/human cationic antimicrobial protein 18 expression by human colon epithelium. Infect Immun 70, 953-963.

68. Paolillo R, Carratelli CR, Sorrentino S, et al. (2009) Immunomodulatory effects of Lactobacillus plantarum on human colon cancer cells. Int Immunopharmacol 9, 1265-1271.

69. Habil N, Abate W, Beal J, et al. (2014) Heat-killed probiotic bacteria differentially regulate colonic epithelial cell production of human beta-defensin-2: dependence on inflammatory cytokines. Benef Microbes 5, 483-495.

70. Wang G, Feng Y, Wang Y, et al. (2003) [Bifidobacterium cell wall proteins induced beta-defensin 2 mRNA expression in human intestinal epithelial cells]. J Sichuan Univ Sci Ed 34, 622-624.

71. Wehkamp J, Harder J, Wehkamp K, et al. (2004) NF-kB-and AP-1-mediated induction of human beta defensin-2 in intestinal epithelial cells by Escherichia coli Nissle 1917: a novel effect of a probiotic bacterium. Infect Immun $\mathbf{7 2}$, 5750-5758.

72. McGuckin MA, Linden SK, Sutton P, et al. (2011) Mucin dynamics and enteric pathogens. Nat Rev Microbiol 9, 265-278.

73. Mack DR, Ahrne S, Hyde L, et al. (2003) Extracellular MUC3 mucin secretion follows adherence of Lactobacillus strains to intestinal epithelial cells in vitro. Gut 52, 827-833.

74. Mack DR, Michail S, Wei S, et al. (1999) Probiotics inhibit enteropathogenic $E$. coli adherence in vitro by inducing intestinal mucin gene expression. Am J Physiol 276, G941-G950.

75. Smirnova MG, Guo L, Birchall JP, et al. (2003) LPS up-regulates mucin and cytokine mRNA expression and stimulates mucin and cytokine secretion in goblet cells. Cell Immunol 221, 42-49.

76. Cani PD, Possemiers S, Van de Wiele T, et al. (2009) Changes in gut microbiota control inflammation in obese mice through a mechanism involving GLP-2-driven improvement of gut permeability. Gut 58, 1091-1103.

77. Cani PD, Amar J, Iglesias MA, et al. (2007) Metabolic endotoxemia initiates obesity and insulin resistance. Diabetes $\mathbf{5 6}$, 1761-1772.

78. Wellen KE \& Hotamisligil GS (2005) Inflammation, stress, and diabetes. J Clin Invest 115, 1111-1119.

79. Wellen KE \& Hotamisligil GS (2003) Obesity-induced inflammatory changes in adipose tissue. J Clin Invest 112, $1785-1788$

80. Laugerette F, Vors C, Geloen A, et al. (2011) Emulsified lipids increase endotoxemia: possible role in early postprandial low-grade inflammation. J Nutr Biochem 22, 53-59.

81. Erridge C, Attina T, Spickett CM, et al. (2007) A high-fat meal induces low-grade endotoxemia: evidence of a novel mechanism of postprandial inflammation. Am J Clin Nutr 86, 1286-1292. 
82. Cani PD, Bibiloni R, Knauf C, et al. (2008) Changes in gut microbiota control metabolic endotoxemia-induced inflammation in high-fat diet-induced obesity and diabetes in mice. Diabetes 57, 1470-1481.

83. Cani PD, Neyrinck AM, Fava F, et al. (2007) Selective increases of bifidobacteria in gut microflora improve highfat-diet-induced diabetes in mice through a mechanism associated with endotoxaemia. Diabetologia 50, 2374-2383.

84. Ley RE, Backhed F, Turnbaugh P, et al. (2005) Obesity alters gut microbial ecology. Proc Natl Acad Sci U S A 102, 11070-11075.

85. Turnbaugh PJ, Backhed F, Fulton L, et al. (2008) Dietinduced obesity is linked to marked but reversible alterations in the mouse distal gut microbiome. Cell Host Microbe 3, 213-223.

86. Waldram A, Holmes E, Wang Y, et al. (2009) Top-down systems biology modeling of host metabotype-microbiome associations in obese rodents. J Proteome Res 8, 2361-2375.

87. Cani PD \& Delzenne NM (2009) Interplay between obesity and associated metabolic disorders: new insights into the gut microbiota. Curr Opin Pharmacol 9, 737-743.

88. Wang ZT, Yao YM, Xiao GX, et al. (2004) Risk factors of development of gut-derived bacterial translocation in thermally injured rats. World J Gastroenterol 10, 1619-1624.

89. Wang Z, Xiao G, Yao Y, et al. (2006) The role of bifidobacteria in gut barrier function after thermal injury in rats. J Trauma 61, 650-657.

90. Griffiths EA, Duffy LC, Schanbacher FL, et al. (2004) In vivo effects of bifidobacteria and lactoferrin on gut endotoxin concentration and mucosal immunity in Balb/c mice. Dig Dis Sci 49, 579-589.

91. Zhang W, Gu Y, Chen Y, et al. (2010) Intestinal flora imbalance results in altered bacterial translocation and liver function in rats with experimental cirrhosis. Eur J Gastroenterol Hepatol 22, 1481-1486.

92. Wang $\mathrm{H}$, Yu M, Ochani $\mathrm{M}$, et al. (2003) Nicotinic acetylcholine receptor alpha7 subunit is an essential regulator of inflammation. Nature 421, 384-388.

93. Muccioli GG, Naslain D, Backhed F, et al. (2010) The endocannabinoid system links gut microbiota to adipogenesis. Mol Syst Biol 6, 392.

94. Pachikian BD, Neyrinck AM, Deldicque L, et al. (2010) Changes in intestinal bifidobacteria levels are associated with the inflammatory response in magnesium-deficient mice. J Nutr 140, 509-514.

95. Everard A, Lazarevic V, Derrien M, et al. (2011) Responses of gut microbiota and glucose and lipid metabolism to prebiotics in genetic obese and diet-induced leptinresistant mice. Diabetes 60, 2775-2786.

96. Delzenne NM \& Cani PD (2011) Gut microbiota and the pathogenesis of insulin resistance. Curr Diab Rep 11, 154-159.

97. Delzenne NM \& Cani PD (2011) Interaction between obesity and the gut microbiota: relevance in nutrition. Annu Rev Nutr 31, 15-31.

98. Delzenne NM, Neyrinck AM, Backhed F, et al. (2011) Targeting gut microbiota in obesity: effects of prebiotics and probiotics. Nat Rev Endocrinol 9, 639-646.

99. Cani PD \& Delzenne NM (2011) The gut microbiome as therapeutic target. Pharmacol Ther 130, 202-212.

100. Parnell JA \& Reimer RA (2009) Weight loss during oligofructose supplementation is associated with decreased ghrelin and increased peptide $\mathrm{YY}$ in overweight and obese adults. Am J Clin Nutr 89, 1751-1759.

101. Malaguarnera M, Vacante M, Antic T, et al. (2012) Bifidobacterium longum with fructo-oligosaccharides in patients with non alcoholic steatohepatitis. Dig Dis Sci 57, 545-553.
102. Dewulf EM, Cani PD, Claus SP, et al. (2012) Insight into the prebiotic concept: lessons from an exploratory, double blind intervention study with inulin-type fructans in obese women. Gut 62, 1112-1121.

103. Cani PD \& Van Hul M (2015) Novel opportunities for nextgeneration probiotics targeting metabolic syndrome. Curr Opin Biotechnol 32, 21-27.

104. Yun SI, Park HO \& Kang JH (2009) Effect of Lactobacillus gasseri BNR17 on blood glucose levels and body weight in a mouse model of type 2 diabetes. $J$ Appl Microbiol 107, $1681-1686$

105. Kang JH, Yun SI \& Park HO (2010) Effects of Lactobacillus gasseri BNR17 on body weight and adipose tissue mass in diet-induced overweight rats. J Microbiol 48, 712-714.

106. Takemura N, Okubo T \& Sonoyama K (2010) Lactobacillus plantarum strain no. 14 reduces adipocyte size in mice fed high-fat diet. Exp Biol Med (Maywood) 235, 849-856.

107. Aronsson L, Huang Y, Parini P, et al. (2010) Decreased fat storage by Lactobacillus paracasei is associated with increased levels of angiopoietin-like 4 protein (ANGPTL4). PLOS ONE 5, e13087.

108. Arora T, Anastasovska J, Gibson G, et al. (2012) Effect of Lactobacillus acidophilus NCDC 13 supplementation on the progression of obesity in diet induced obese mice. Br J Nutr 108, 1382-1389.

109. Naito E, Yoshida Y, Makino K, et al. (2011) Beneficial effect of oral administration of Lactobacillus casei strain Shirota on insulin resistance in diet-induced obesity mice. I Appl Microbiol 110, 650-657.

110. Kadooka Y, Sato M, Imaizumi K, et al. (2010) Regulation of abdominal adiposity by probiotics (Lactobacillus gasseri SBT2055) in adults with obese tendencies in a randomized controlled trial. Eur J Clin Nutr 64, 636-643.

111. Kadooka Y, Sato M, Ogawa A, et al. (2013) Effect of Lactobacillus gasseri SBT2055 in fermented milk on abdominal adiposity in adults in a randomised controlled trial. Br J Nutr 110, 1696-1703.

112. Jung SP, Lee KM, Kang JH, et al. (2013) Effect of Lactobacillus gasseri BNR17 on overweight and obese adults: a randomized, double-blind clinical trial. Korean J Fam Med 34, 80-89.

113. Luoto R, Kalliomaki M, Laitinen K, et al. (2010) The impact of perinatal probiotic intervention on the development of overweight and obesity: follow-up study from birth to 10 years. Int J Obes 34, 1531-1537.

114. Angelakis E, Bastelica D, Ben Amara A, et al. (2012) An evaluation of the effects of Lactobacillus ingluviei on body weight, the intestinal microbiome and metabolism in mice. Microb Pathog 52, 61-68.

115. An HM, Park SY, Lee do K, et al. (2011) Antiobesity and lipidlowering effects of Bifidobacterium spp. in high fat dietinduced obese rats. Lipids Health Dis 10, 116.

116. Chen JJ, Wang R, Li XF, et al. (2011) Bifidobacterium longum supplementation improved high-fat-fed-induced metabolic syndrome and promoted intestinal Reg I gene expression. Exp Biol Med (Maywood) 236, 823-831.

117. Amar J, Chabo C, Waget A, et al. (2011) Intestinal mucosal adherence and translocation of commensal bacteria at the early onset of type 2 diabetes: molecular mechanisms and probiotic treatment. EMBO Mol Med 3, 559-572.

118. Collado MC, Meriluoto J \& Salminen S (2007) Role of commercial probiotic strains against human pathogen adhesion to intestinal mucus. Lett Appl Microbiol 45, 454-460.

119. Putaala H, Salusjarvi T, Nordstrom M, et al. (2008) Effect of four probiotic strains and Escherichia coli O157: H7 on tight junction integrity and cyclo-oxygenase expression. Res Microbiol 159, 692-698. 
120. Everard A, Belzer C, Geurts L, et al. (2013) Cross-talk between Akkermansia muciniphila and intestinal epithelium controls diet-induced obesity. Proc Natl Acad Sci U S A 110, 9066-9071.

121. Shin NR, Lee JC, Lee HY, et al. (2013) An increase in the Akkermansia spp. population induced by metformin treatment improves glucose homeostasis in diet-induced obese mice. Gut $\mathbf{6 3}, 727-735$.

122. Neu J \& Walker WA (2011) Necrotizing enterocolitis. N EnglJ Med 364, 255-264.

123. Ganguli K \& Walker WA (2011) Probiotics in the prevention of necrotizing enterocolitis. I Clin Gastroenterol 45, S133-S138.

124. AlFaleh K \& Anabrees J (2014) Probiotics for prevention of necrotizing enterocolitis in preterm infants. The Cochrane Database of Systematic Reviews 2014, issue 16, CD005496.

125. Deshpande G, Rao S, Patole S, et al. (2010) Updated metaanalysis of probiotics for preventing necrotizing enterocolitis in preterm neonates. Pediatrics 125, 921-930.

126. Mihatsch WA (2011) What is the power of evidence recommending routine probiotics for necrotizing enterocolitis prevention in preterm infants? Curr Opin Clin Nutr Metab Care 14, 302-306.

127. Mihatsch WA, Braegger CP, Decsi T, et al. (2012) Critical systematic review of the level of evidence for routine use of probiotics for reduction of mortality and prevention of necrotizing enterocolitis and sepsis in preterm infants. Clin Nutr 31, 6-15.

128. Anand RJ, Leaphart CL, Mollen KP, et al. (2007) The role of the intestinal barrier in the pathogenesis of necrotizing enterocolitis. Shock 27, 124-133.

129. Emami CN, Petrosyan M, Giuliani S, et al. (2009) Role of the host defense system and intestinal microbial flora in the pathogenesis of necrotizing enterocolitis. Surg Infect (Larchmt) 10, 407-417.

130. Hunter CJ, Upperman JS, Ford HR, et al. (2008) Understanding the susceptibility of the premature infant to necrotizing enterocolitis (NEC). Pediatr Res 63, 117-123.

131. Levy O (2007) Innate immunity of the newborn: basic mechanisms and clinical correlates. Nat Rev Immunol 7, 379-390.

132. Neu J (2007) Gastrointestinal development and meeting the nutritional needs of premature infants. Am J Clin Nutr 85, 629S-634S

133. Sherman MP (2010) New concepts of microbial translocation in the neonatal intestine: mechanisms and prevention. Clin Perinatol 37, 565-579.

134. Sharma R \& Tepas JJ III (2010) Microecology, intestinal epithelial barrier and necrotizing enterocolitis. Pediatr Surg Int 26, 11-21.

135. Agarwal R, Sharma N, Chaudhry R, et al. (2003) Effects of oral Lactobacillus GG on enteric microflora in low-birth-weight neonates. J Pediatr Gastroenterol Nutr 36, 397-402.

136. Chrzanowska-Liszewska D, Seliga-Siwecka J \& Kornacka MK (2012) The effect of Lactobacillus rhamnosus GG supplemented enteral feeding on the microbiotic flora of preterm infants-double blinded randomized control trial. Early Hum Dev 88, 57-60.

137. Costalos C, Skouteri V, Gounaris A, et al. (2003) Enteral feeding of premature infants with Saccharomyces boulardii. Early Hum Dev 74, 89-96.

138. Manzoni P, Mostert M, Leonessa ML, et al. (2006) Oral supplementation with Lactobacillus casei subspecies rhamnosus prevents enteric colonization by Candida species in preterm neonates: a randomized study. Clin Infect Dis $\mathbf{4 2}$, $1735-1742$.
139. Manzoni P (2007) Use of Lactobacillus casei subspecies rhamnosus GG and gastrointestinal colonization by Candida species in preterm neonates. J Pediatr Gastroenterol Nutr $\mathbf{4 5}$, S190-S194.

140. Romeo MG, Romeo DM, Trovato L, et al. (2011) Role of probiotics in the prevention of the enteric colonization by Candida in preterm newborns: incidence of late-onset sepsis and neurological outcome. J Perinatol 31, 63-69.

141. Rouge C, Piloquet H, Butel MJ, et al. (2009) Oral supplementation with probiotics in very-low-birth-weight preterm infants: a randomized, double-blind, placebo-controlled trial. Am J Clin Nutr 89, 1828-1835.

142. Underwood MA, Salzman NH, Bennett SH, et al. (2009) A randomized placebo-controlled comparison of 2 prebiotic/ probiotic combinations in preterm infants: impact on weight gain, intestinal microbiota, and fecal short-chain fatty acids. J Pediatr Gastroenterol Nutr 48, 216-225.

143. Indrio F, Riezzo G, Raimondi F, et al. (2008) The effects of probiotics on feeding tolerance, bowel habits, and gastrointestinal motility in preterm newborns. J Pediatr 152, 801-806.

144. Stratiki Z, Costalos C, Sevastiadou S, et al. (2007) The effect of a bifidobacter supplemented bovine milk on intestinal permeability of preterm infants. Early Hum Dev 83, 575-579.

145. Mohan R, Koebnick C, Schildt J, et al. (2006) Effects of Bifidobacterium lactis Bb12 supplementation on intestinal microbiota of preterm infants: a double-blind, placebocontrolled, randomized study. J Clin Microbiol 44, 4025-4031.

146. Mohan R, Koebnick C, Schildt J, et al. (2008) Effects of Bifidobacterium lactis $\mathrm{Bb} 12$ supplementation on body weight, fecal $\mathrm{pH}$, acetate, lactate, calprotectin, and IgA in preterm infants. Pediatr Res 64, 418-422.

147. Fak F, Ahrne S, Linderoth A, et al. (2008) Age-related effects of the probiotic bacterium Lactobacillus plantarum 299v on gastrointestinal function in suckling rats. Dig Dis Sci 53, 664-671.

148. Preidis GA, Saulnier DM, Blutt SE, et al. (2012) Probiotics stimulate enterocyte migration and microbial diversity in the neonatal mouse intestine. FASEB J 26, 1960-1969.

149. Siggers RH, Siggers J, Boye M, et al. (2008) Early administration of probiotics alters bacterial colonization and limits diet-induced gut dysfunction and severity of necrotizing enterocolitis in preterm pigs. J Nutr 138, 1437-1444.

150. Lee DJ, Drongowski RA, Coran AG, et al. (2000) Evaluation of probiotic treatment in a neonatal animal model. Pediatr Surg Int 16, 237-242.

151. Sherman MP, Bennett SH, Hwang FF, et al. (2004) Neonatal small bowel epithelia: enhancing anti-bacterial defense with lactoferrin and Lactobacillus GG. Biometals 17, 285-289.

152. McVay MR, Boneti C, Habib CM, et al. (2008) Formula fortified with live probiotic culture reduces pulmonary and gastrointestinal bacterial colonization and translocation in a newborn animal model. J Pediatr Surg 43, 25-29.

153. Gareau MG, Jury J, MacQueen G, et al. (2007) Probiotic treatment of rat pups normalises corticosterone release and ameliorates colonic dysfunction induced by maternal separation. Gut 56, 1522-1528.

154. Isolauri E, Kaila M, Arvola T, et al. (1993) Diet during rotavirus enteritis affects jejunal permeability to macromolecules in suckling rats. Pediatr Res 33, 548-553.

155. Isolauri E, Majamaa H, Arvola T, et al. (1993) Lactobacillus casei strain GG reverses increased intestinal permeability induced by cow milk in suckling rats. Gastroenterology $\mathbf{1 0 5}$, $1643-1650$

156. Terpend K, Blaton MA, Candalh C, et al. (1999) Intestinal barrier function and cow's milk sensitization in guinea pigs fed milk or fermented milk. J Pediatr Gastroenterol Nutr $\mathbf{2 8}$, 191-198. 
157. Caplan MS, Miller-Catchpole R, Kaup S, et al. (1999) Bifidobacterial supplementation reduces the incidence of necrotizing enterocolitis in a neonatal rat model. Gastroenterology 117, 577-583.

158. Liu Y, Fatheree NY, Mangalat N, et al. (2012) Lactobacillus reuteri strains reduce incidence and severity of experimental necrotizing enterocolitis via modulation of TLR 4 and NF-kB signaling in the intestine. Am J Physiol Gastrointest Liver Physiol 302, G608-G617.

159. Good M, Sodhi CP, Ozolek JA, et al. (2014) Lactobacillus rhamnosus HNO01 decreases the severity of necrotizing enterocolitis in neonatal mice and preterm piglets: evidence in mice for a role of TLR9. Am J Physiol Gastrointest Liver Physiol 306, G1021-G1032.

160. Khailova L, Dvorak K, Arganbright KM, et al. (2009) Bifidobacterium bifidum improves intestinal integrity in a rat model of necrotizing enterocolitis. Am J Physiol Gastrointest Liver Physiol 297, G940-G949.

161. Underwood MA, Kananurak A, Coursodon CF, et al. (2012) Bifidobacterium bifidum in a rat model of necrotizing enterocolitis: antimicrobial peptide and protein responses. Pediatr Res 71, 546-551.

162. Lin PW, Nasr TR, Berardinelli AJ, et al. (2008) The probiotic Lactobacillus GG may augment intestinal host defense by regulating apoptosis and promoting cytoprotective responses in the developing murine gut. Pediatr Res 64, 511-516.

163. Hunter CJ, Williams M, Petrosyan M, et al. (2009) Lactobacillus bulgaricus prevents intestinal epithelial cell injury caused by Enterobacter sakazakii-induced nitric oxide both in vitro and in the newborn rat model of necrotizing enterocolitis. Infect Immun 77, 1031-1043.

164. Goncalves FLL, Soares LMM, Figueira RL, et al. (2015) Evaluation of the expression of I-FABP and L-FABP in a necrotizing enterocolitis model after the use of Lactobacillus acidophilus. J Pediatr Surg 50, 543-549.

165. Liu Y, Fatheree NY, Mangalat N \& Rhoads JM (2010) Humanderived probiotic Lactobacillus reuteri strains differentially reduce intestinal inflammation. Am J Physiol Gastrointest Liver Physiol 299, G1087-G1096.

166. Cilieborg MS, Thymann T, Siggers R, et al. (2011) The incidence of necrotizing enterocolitis is increased following probiotic administration to preterm pigs. J Nutr 141, 223-230.

167. Guenther K, Straube E, Pfister W, et al. (2010) Severe sepsis after probiotic treatment with Escherichia coli NISSLE 1917. Pediatr Infect Dis J 29, 188-189.

168. Land MH, Rouster-Stevens K, Woods CR, et al. (2005) Lactobacillus sepsis associated with probiotic therapy. Pediatrics 115, 178-181.

169. Levy RL, Olden KW, Naliboff BD, et al. (2006) Psychosocial aspects of the functional gastrointestinal disorders. Gastroenterology 130, 1447-1458.

170. Koloski NA, Talley NJ \& Boyce PM (2002) Epidemiology and health care seeking in the functional GI disorders: a population-based study. Am J Gastroenterol 97, 2290-2299.

171. Kassinen A, Krogius-Kurikka L, Makivuokko H, et al. (2007) The fecal microbiota of irritable bowel syndrome patients differs significantly from that of healthy subjects. Gastroenterology 133, 24-33.

172. Rajilic-Stojanovic M, Biagi E, Heilig HGHJ, et al. (2011) Global and deep molecular analysis of microbiota signatures in fecal samples from patients with irritable bowel syndrome. Gastroenterology 141, 1792-1801.

173. Chassard C, Dapoigny M, Scott KP, et al. (2012) Functional dysbiosis within the gut microbiota of patients with constipated-irritable bowel syndrome. Aliment Pharmacol Ther 35, 828-838.
174. Carroll IM, Ringel-Kulka T, Siddle JP, et al. (2012) Alterations in composition and diversity of the intestinal microbiota in patients with diarrhea-predominant irritable bowel syndrome. Neurogastroenterol Motil 24, 521-530.

175. Jeffery IB, O’Toole PW, Ohman L, et al. (2012) An irritable bowel syndrome subtype defined by species-specific alterations in faecal microbiota. Gut 61, 997-1006.

176. Sundin J, Rangel I, Fuentes S, et al. (2015) Altered faecal and mucosal microbial composition in post-infectious irritable bowel syndrome patients correlates with mucosal lymphocyte phenotypes and psychological distress. Aliment Pharmacol Ther 41, 342-351.

177. Tojo GR, Suarez GA, Ruas MP, et al. (2014) [Irritable Bowel Syndrome; gut microbiota and probiotic therapy]. Nutr Hosp 31, 83-88.

178. Lee KN \& Lee OY (2014) Intestinal microbiota in pathophysiology and management of irritable bowel syndrome. World J Gastroenterol 20, 8886.

179. Theodorou V, it-Belgnaoui A, Agostini S, et al. (2014) Effect of commensals and probiotics on visceral sensitivity and pain in irritable bowel syndrome. Gut Microbes 5, 430-436.

180. Hyland NP, Quigley EMM \& Brint E (2014) Microbiota-host interactions in irritable bowel syndrome: epithelial barrier, immune regulation and brain-gut interactions. World $J$ Gastroenterol 20, 8859

181. Nebot-Vivinus M, Harkat C, Bzioueche H, et al. (2014) Multispecies probiotic protects gut barrier function in experimental models. World J Gastroenterol 20, 6832

182. Laval L, Martin R, Natividad JN, et al. (2015) Lactobacillus rbamnosus CNCM I-3690 and the commensal bacterium Faecalibacterium prausnitzii A2-165 exhibit similar protective effects to induced barrier hyper-permeability in mice. Gut Microbes 6, 1-6839.

183. Wang H, Gong J, Wang W, et al. (2014) Are there any different effects of Bifidobacterium, Lactobacillus and Streptococcus on intestinal sensation, barrier function and intestinal immunity in PI-IBS mouse model. PLOS ONE 9, e90153.

184. Da Silva S, Robbe-Masselot C, it-Belgnaoui A, et al. (2014) Stress disrupts intestinal mucus barrier in rats via mucin O-glycosylation shift: prevention by a probiotic treatment. Am J Physiol Gastrointest Liver Physiol 307, G420-G429.

185. Agostini S, Goubern M, Tondereau V, et al. (2012) A marketed fermented dairy product containing Bifidobacterium lactis CNCM I-2494 suppresses gut hypersensitivity and colonic barrier disruption induced by acute stress in rats. Neurogastroenterol Motil 24, 376-e172.

186. Koenig J \& Brummer RJ (2014) Alteration of the intestinal microbiota as a cause of and a potential therapeutic option in irritable bowel syndrome. Benef Microbes 5, 247-261.

187. Whelan K (2011) Probiotics and prebiotics in the management of irritable bowel syndrome: a review of recent clinical trials and systematic reviews. Curr Opin Clin Nutr Metab Care 14, 581-587.

188. Moayyedi P, Ford AC, Talley NJ, et al. (2010) The efficacy of probiotics in the treatment of irritable bowel syndrome: a systematic review. Gut 59, 325-332.

189. Hoveyda N, Heneghan C, Mahtani KR, et al. (2009) A systematic review and meta-analysis: probiotics in the treatment of irritable bowel syndrome. BMC Gastroenterol $\mathbf{9}, 15$.

190. Gibson GR, Brummer RJ, Isolauri E, et al. (2011) The design of probiotic studies to substantiate health claims. Gut Microbes 2, 299-305.

191. Clarke G, Cryan JF, Dinan TG, et al. (2012) Review article: probiotics for the treatment of irritable bowel syndrome-focus on lactic acid bacteria. Aliment Pharmacol Ther 35, 403-413. 
192. Saulnier DM, Riehle K, Mistretta T, et al. (2011) Gastrointestinal microbiome signatures of pediatric patients with irritable bowel syndrome. Gastroenterology 141, 1782-1791.

193. Vanhoutvin SALW, Troost FJ, Kilkens TOC, et al. (2009) The effects of butyrate enemas on visceral perception in healthy volunteers. Neurogastroenterol Motil 21, 952-e76.

194. MacDonald TT, Monteleone I, Fantini MC, et al. (2011) Regulation of homeostasis and inflammation in the intestine. Gastroenterology 140, 1768-1775.

195. Pastorelli L, De Salvo C, Mercado JR, et al. (2013) Central role of the gut epithelial barrier in the pathogenesis of chronic intestinal inflammation: lessons learned from animal models and human genetics. Front Immunol 4, 280.

196. Beaurepaire C, Smyth D \& McKay DM (2009) Interferongamma regulation of intestinal epithelial permeability. J Interferon Cytokine Res 29, 133-144.

197. Gibson PR (2004) Increased gut permeability in Crohn's disease: is TNF the link? Gut 53, 1724-1725.

198. Prasad S, Mingrino R, Kaukinen K, et al. (2005) Inflammatory processes have differential effects on claudins 2, 3 and 4 in colonic epithelial cells. Lab Invest 85, 1139-1162.

199. Biancheri P, Di Sabatino A, Corazza GR, et al. (2013) Proteases and the gut barrier. Cell Tissue Res 351, 269-280.

200. Prantera C, Scribano ML, Falasco G, et al. (2002) Ineffectiveness of probiotics in preventing recurrence after curative resection for Crohn's disease: a randomised controlled trial with Lactobacillus GG. Gut 51, 405-409.

201. Marteau P, Lemann M, Seksik P, et al. (2006) Ineffectiveness of Lactobacillus johnsonii LA1 for prophylaxis of postoperative recurrence in Crohn's disease: a randomised, double blind, placebo controlled GETAID trial. Gut 55, 842-847.

202. Van Gossum A, Dewit O, Louis E, et al. (2007) Multicenter randomized-controlled clinical trial of probiotics (Lactobacillus johnsonii, LA1) on early endoscopic recurrence of Crohn's disease after ileo-caecal resection. Inflamm Bowel Dis 13, 135-142.

203. Chermesh I, Tamir A, Reshef R, et al. (2007) Failure of Synbiotic 2000 to prevent postoperative recurrence of Crohn's disease. Dig Dis Sci 52, 385-389.

204. Steed H, Macfarlane GT, Blackett KL, et al. (2010) Clinical trial: the microbiological and immunological effects of synbiotic consumption - a randomized double-blind placebo-controlled study in active Crohn's disease. Aliment Pharmacol Ther 32, 872-883.

205. Ghouri YA, Richards DM, Rahimi EF, et al. (2014) Systematic review of randomized controlled trials of probiotics, prebiotics, and synbiotics in inflammatory bowel disease. Clin Exp Gastroenterol 7, 473.

206. Whelan K \& Quigley EMM (2013) Probiotics in the management of irritable bowel syndrome and inflammatory bowel disease. Curr Opin Gastroenterol 29, 184-189.

207. Kruis W, Schutz E, Fric P, et al. (1997) Double-blind comparison of an oral Escherichia coli preparation and mesalazine in maintaining remission of ulcerative colitis. Aliment Pharmacol Ther 11, 853-858.

208. Veerappan GR, Betteridge J \& Young PE (2012) Probiotics for the treatment of inflammatory bowel disease. Curr Gastroenterol Rep 14, 324-333.

209. Yan F, Cao H, Cover TL, et al. (2011) Colon-specific delivery of a probiotic-derived soluble protein ameliorates intestinal inflammation in mice through an EGFR-dependent mechanism. J Clin Invest 121, 2242.

210. Toumi R, Abdelouhab K, Rafa H, et al. (2013) Beneficial role of the probiotic mixture Ultrabiotique on maintaining the integrity of intestinal mucosal barrier in DSS-induced experimental colitis. Immunopharmacol Immunotoxicol 35, 403-409.

211. Mennigen R, Nolte K, Rijcken E, et al. (2009) Probiotic mixture VSL\#3 protects the epithelial barrier by maintaining tight junction protein expression and preventing apoptosis in a murine model of colitis. Am J Physiol Gastrointest Liver Physiol 296, G1140-G1149.

212. Srutkova D, Schwarzer M, Hudcovic T, et al. (2015) Bifidobacterium longum CCM 7952 promotes epithelial barrier function and prevents acute DSS-induced colitis in strictly strain-specific manner. PLOS ONE 10, e0134050.

213. Ahl D, Liu H, Schreiber O, et al. (2016) Lactobacillus reuteri increases mucus thickness and ameliorates dextran sulphate sodium-induced colitis in mice. Acta Physiol (Oxf) 217, 300-310.

214. Ewaschuk JB, Diaz H, Meddings L, et al. (2008) Secreted bioactive factors from Bifidobacterium infantis enhance epithelial cell barrier function. Am J Physiol Gastrointest Liver Physiol 295, G1025-G1034.

215. Yan F, Liu L, Dempsey PJ, et al. (2013) A Lactobacillus rhamnosus GG-derived soluble protein, $\mathrm{p} 40$, stimulates ligand release from intestinal epithelial cells to transactivate epidermal growth factor receptor. J Biol Chem 288, 30742-30751.

216. Rescigno M (2011) The intestinal epithelial barrier in the control of homeostasis and immunity. Trends Immunol 32, 256-264.

217. Atarashi K, Tanoue T, Shima T, et al. (2011) Induction of colonic regulatory $\mathrm{T}$ cells by indigenous Clostridium species. Science 331, 337-341.

218. Atarashi K, Tanoue T, Oshima K, et al. (2013) Treg induction by a rationally selected mixture of Clostridia strains from the human microbiota. Nature 500, 232-236.

219. Furusawa Y, Obata Y, Fukuda S, et al. (2014) Commensal microbe-derived butyrate induces the differentiation of colonic regulatory T cells. Nature 504, 446-450.

220. Khoruts A, Dicksved J, Jansson JK, et al. (2010) Changes in the composition of the human fecal microbiome after bacteriotherapy for recurrent Clostridium difficile-associated diarrhea. J Clin Gastroenterol 44, 354-360.

221. Borody TJ \& Khoruts A (2012) Fecal microbiota transplantation and emerging applications. Nat Rev Gastroenterol Hepatol 9, 88-96.

222. Borody TJ, Warren EF, Leis S, et al. (2003) Treatment of ulcerative colitis using fecal bacteriotherapy. J Clin Gastroenterol 37, 42-47.

223. Vrieze A, Van Nood E, Holleman F, et al. (2012) Transfer of intestinal microbiota from lean donors increases insulin sensitivity in individuals with metabolic syndrome. Gastroenterology 143, 913-916.

224. Spiller RC, Jenkins D, Thornley JP, et al. (2000) Increased rectal mucosal enteroendocrine cells, $\mathrm{T}$ lymphocytes, and increased gut permeability following acute Campylobacter enteritis and in post-dysenteric irritable bowel syndrome. Gut 47, 804-811.

225. Panzer AR \& Lynch SV (2015) Influence and effect of the human microbiome in allergy and asthma. Curr Opin Rheumatol 27, 373-380.

226. Rosenfeldt V, Benfeldt E, Valerius NH, et al. (2004) Effect of probiotics on gastrointestinal symptoms and small intestinal permeability in children with atopic dermatitis. J Pediatr 145, 612-616.

227. McNaught CE, Woodcock NP, Anderson ADG, et al. (2005) A prospective randomised trial of probiotics in critically ill patients. Clin Nutr 24, 211-219.

228. Klaenhammer TR, Kleerebezem M, Kopp MV, et al. (2012) The impact of probiotics and prebiotics on the immune system. Nat Rev Immunol 12, 728-734. 